Such experiments are now in progress. Evidence suggests that the light effect is dependent, to some extent, on temperature and salinity relations. Summer animals, either 8- or 16-hr. groups, respond differently when maintained under different combinations of temperature and salinity. The tendency is for 8-hr. groups to increase the percentage difference of weight-specific oxygen consumption, when compared with 16-hr. and control groups, as temperature increases and salinity decreases.

Acknowledgments are due to the National Research Council of Canada and the National Science Foundation of the United States.

PaUl A. Dehnel

Department of Zoology, University of British Columbia, Vancouver 8, B.C. March 3.

${ }^{1}$ Prosser, C. L., Biol. Rev., 30, 229 (1955).

'Hoar, W. S., Nature, 178, 364 (1956).

'Wennesland, R., Science, 114, 100 (1951).

\section{Effect of Stress and Cortisone on the Cytomorphology of Pituitary Grafts in Rats}

IN the course of previous investigations ${ }^{1-3}$ it was demonstrated that following stress (administration of formalin, intensive dehydration) the number of basophil cells in the adenohypophysis of rats increased considerably. For the development of this phenomenon the presence of the adrenal gland is needed : thus if formalin stress is applied in adrenalectomized animals, basophil hyperplasia fails to develop. The importance of the adrenal cortex is also supported by the fact that cortisone treatment also increases the number of the basophils ${ }^{4}$.

Recent work suggests that the hypothalamus plays an important part in the regulation of the function of the adenohypophysis ${ }^{5}$. It was of interest, therefore, to examine whether stress or cortisone can influence the cytomorphological picture of the adenohypophysis if its direct connexion with the hypothalamus is interrupted.

To elucidate this problem, the adenohypophysis of rats was transplanted into the anterior chamber of the eye. These experimental conditions seemed more suitable than section of the stalk, as the transplanted pituitary vascularizes well, whereas after section of the stalk disorders of the blood supply-occasionally leading to necrosis and fibrosis-may occur'.

The experiments were carried out on fifty female albino rats each weighing 150-200 gm., kept on a mixed diet. The hypophysectomy was performed under ether anæsthesia by the usual parapharingeal approach, and the adenohypophysis was transplanted into the anterior chamber of the left eye, the neurohypophysis being discarded. The experiments were started one month after the operation. $10 \mathrm{mgm}$. cortisone ('Adreson', Organon) was administered subcutaneously to each of ten rats every day for eight days. Ten other rats were treated with formalin $(0.5 \mathrm{ml}$. of 2 per cent formalin administered subcutaneously every day for one week, and twice daily after the eighth day). Thirty rats were used as controls. The animals treated with cortisone were killed on the eighth day, whereas the administration of formalin was continued until the animals died. In addition, ten untreated non-operated controls and two groups of ten non-operated animals, treated on identical conditions with cortisone and formalin respectively, were examined histologically. The hypophyses were fixed in Susa solution and embedded in paraffin. The serial sections were stained by Goldberg and Chaikoff's method?

Complete disappearance of the basophil cells could be observed in the pituitary grafts of the untreated hypophysectomized rats. The number of the eosinophils also decreased considerably, so that only a few markedly degranulated eosinophil cells could be found. Chromophobes predominated. These findings are in agreement with the results of other authors ${ }^{8}$. The hypophyses vascularized well, and among the cell cords broad sinusoids containing blood were seen. Necrosis could not be detected.

Administration of formalin did not alter the cytomorphological picture of the pituitary grafts. In normal rats an intensive basophil hyperplasia develops in the adenohypophysis after formalin treatment, whereas in the implanted animals no basophils could be observed.

The basophil cells reappeared in the pituitary grafts of the animals treated with cortisone. In normal rats cortisone administration resulted in an increase of basophils. The cells became hypertrophied, the basophil granules of their cytoplasm became homogeneous, stained deep blue and in some places resembled Crooke cells. In the grafts some of the basophils were homogeneous, the granules condensed perinuclearly and in other places became hypertrophied, and finely degranulated basophils could be observed.

Our investigations show that for the development of basophil hyperplasia due to formalin stress direct connexion between the adenohypophysis and the hypothalamus is necessary. On the other hand, the effect of cortisone on the cytomorphology of the adenohypophysis does not occur through the hypothalamus but is exerted directly on the basophil cells of the pituitary.

In the course of retransplantation of the grafted, degranulated and chromophobic pituitary under the median eminence, Nikitovitch-Winer and Everett ${ }^{\circ}$ observed the reappearance of the basophils. This morphological change occurred simultaneously with the restoration of the function of the adenohypophysis. Our investigations point to the fact that the reappearance of the basophils after administration of cortisone occurs in the case of pituitary grafts also. The alternative view that these cytomorphological changes may be of degenerative or regressive nature, or that they may result from the alteration of the functional state of the transplanted pituitary, must now be analysed.

\section{K. Kovács \\ M. A. DÁvid}

I. W. HORVATH

First Department of Medicine,

Medical University,

Szeged, Hungary.

March 12.

${ }^{2}$ Bachrach, D. Kovács, K., Dávid, M., Horváth, E., and Korpássy, B., Acta Morphol., Hung., 4, 429 '(1954).

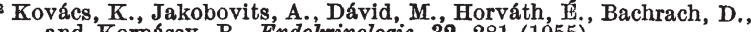
and Korpássy, B., Endokrinologie, 32, 281 (1955).

${ }^{3}$ Kovács, K., Dávid, M., and Korpássy, B., Lancet, i, 638 (1957).

- Kovács, K., Dávid, M. A., and Korpássy, B., Endokrinologie (in the press)

"Harris, G. W. "Neural Control of the Pituitary Gland" (Edward Arnold, Ltả., London, 1955).

- Greep, R. O., and Barrnett, R. J., Endocrinology, 49, 172 (1951).

'Goldberg, R. C., and Chaikoff, I. L., Anat. Rec., 112, 265 (1952).

8 Siperstein, E. R., and Greer, M. A., J. Nat. Cancer Inst., 17, 569 (1956).

- Nikitovitch-Winer, M., and Everett, J. W., Nature, 180, 1434 (1957). 